\title{
Rekreasyonel Spor Tesisleri Üyelerinin Algılanan Hizmet Kalitesi Düzeylerinin İncelenmesi
}

\author{
DOI: $10.26466 /$ opus. 677521
}

*

\begin{abstract}
Arif Çetin* - Ayșe Demir **
*Dr. Öğr. Gör., İstanbul Aydın Üniversitesi Spor Bilimleri Fakültesi İstanbul/Türkiye

E-Posta: arifcetin1985@gmail.com

ORCID: $\quad 0000-0002-7430-4830$

${ }^{* *}$ Dr. Öğr. Gör., İstanbul Aydın Üniversitesi Spor Bilimleri Fakültesi İstanbul/Türkiye

E-Posta: aysedemir@aydin.edu.tr

ORCID: $\quad \underline{0000-0002-3856-0498}$
\end{abstract}

\section{Öz}

Bu çalışmanın amacı spor merkezi üyelerinin beklentilerini ve algzlanan hizmet kalitesi düzeylerini öngören değişkenlerin araştırılmasıdır. Araştırmanın örneklemini spor tesisleri üyeleri arasında gönüllü olarak katılan \%64 kadın (n: 238) ve \%36 erkek (n: 134) katılımcı oluşturmuştur. Araştırmada veri toplama aracı olarak "Rekreasyonel Sporda Hizmet Kalitesi Ölçeği-38" kullanılmıştır. Ölçek 10 alt boyuta sahiptir ve 38 maddeden oluşmaktadır. Verilerin analizinde ölçeğin güvenirlik düzeyini belirlemek için $t$ testi, tek yönlü varyans analizi, Cronbach alfa testi kullanılmıştır. Bu çalışmanın sonuçlarl, kadınların "bilgi", "program çeşitliliği" ve "çalışma süresi" alt boyutlarının hizmet kalitesi düzeyinin erkeklerden anlamlı düzeyde daha yüksek olduğunu göstermektedir. Hizmet Kalitesi Ölçeği tüm alt boyutlar ile üyelerin yaş grupları, haftalık spor günü sayısı ve spor yılı arasında anlamlı farklılıklar olduğu tespit edilmiştir. Sonuç olarak, sosyal değişimlerin ve dönüşümlerin bilinçli tüketicileri ortaya çıkarmada aktif bir rol oynadığ d düşünülebilir. Bu nedenle üyeler spor merkezlerini yalnızca tek bir boyutta değerlendirmedikleri söylenebilir. Dolayıslyla yerel yönetimler spor merkezlerinin fiziksel unsurlarını yanında sosyal ortamları da spor tesislerinde planlamalıdır.

Anahtar Kelimeler: spor tesisleri, hizmet kalitesi, müşteri beklentisi, spor hizmeti, yerel yönetim 


\title{
Examining the Perceived Service Quality Levels of Recreational Sports Facilities Members
}

\begin{abstract}
This study aims to investigate the variables that predict the sports centre members' expectations and perceived service quality levels. The sample of the study was $64 \%$ female (n: 238) and $36 \%$ male ( $n$ : 134) participants who are voluntary participated among members of sports facilities. In the research, "The Scale of Service Quality in Recreational Sport-38" is used as a data collection tool. The Scale has $10 \mathrm{sub}$ dimensions and consists of 38 articles. In the analysis of the data, $t$ test, one-way analysis of variance, Cronbach alpha test were used to determine the reliability level of the scale. The results of this study show that the service quality level of "information", "program variety" and "working time" subdimensions of women were significantly higher than men. It was ascertained that there were significant differences were found in the all sub-dimensions of the Scale of Service Quality, age groups of members, number of weekly sports days and sports year of the participants. As a result, it can be thought that social changes and transformations play an active role in uncovering conscious consumers. For this reason, it can be said that members do not evaluate sports facilities in only one dimension. Therefore, local governments should plan social environments in sports facilities as well as physical elements.
\end{abstract}

Keywords: sport facilities, service quality, customer expectation, sport service, local government 


\section{Giriş}

Günümüzde modern şehir yaşamıyla birlikte egzersiz popüler bir aktivite haline gelmiş olup hem kamu hem özel sektör müşterilerine spor merkezlerinde çok çeşitli hizmetler sunmaktadır. Bununla birlikte bu işletmeler piyasalardaki artan rekabet nedeniyle mali zorluklarla da karşı karşıyadır. Bu nedenle, spor merkezlerinin hizmet kalitesi mali zorlukların çözümünde en önemli faktör olarak ortaya çıkmaktadır (Jung ve Choi, 2016).

Modern şehir hayatında insanlar fiziksel ve zihinsel açıdan yaşadığı ortama ayak uydurabilmesi insanlığın öne çıkan en belirgin özelliği olsa da bu geçiş süreci çok kolay olmamaktadır. Özellikle metropol şehirlerindeki yaşam koşulları düşünüldüğünde bireylerin fiziksel aktiviteye katılması lüks sayılmaktadır. Rutinleşen çalışma hayatı ciddi fiziksel yorgunluklarla beraber psikolojik yıpranmalara da yol açmaktadır. İşte bu yüzden İstanbul genelinde yerel yönetimler ve özel şirketler tarafından 590 fitness salonu, 310 pilates stüdyosu, 113 bilardo salonu, 110 wellness salonu, 80 yüzme havuzu gibi spor tesisleri olmak üzere toplam 1203 tesisle bireylerin ihtiyaçlarına cevap verilmektedir.

Spora olan bu ilgi, fiziksel, psikolojik ve sosyal refahla ortaya çikan son yirmi yılda olumlu bir şekilde gelişti ve insanların yaşam kalitesinin artmasına yol açtı. Spor yönetimi kavramı, içerdiği çok sayıda görev ve eylem nedeniyle daha zorlu hale gelmiştir ve spor hizmetlerini geliştirmek amaciyla yeterli kalite değerlendirme programlarının uygulanmasına giderek artan bir ihtiyaç vardır (Castillo-Rodriguez, Onetti-Onetti ve Chinchilla-Minguet, 2019).

Toplumun daha yüksek yoksulluk seviyeleri yaşadığı dönemlere aykırı olarak, sağlık, esenlik ve egzersiz açısından yüksek yaşam kalitesini hedefleyen gözle görülür bir toplumsal olgu ortaya çıkmıştır (Rhee vd., 2006). Buna ek olarak, beş günlük iş haftası nedeniyle boş zamanlarının artması ve yaşlanan toplumların sağlık arzusunun artması gibi faktörler de egzersize katılım artmıştır (Kim, 2006). Sağlı̆̆a olan ilgi arttıkça, çeşitli spor programlarının keyfini çıarabileceğiniz farklı spor merkezleri, modern bireylerin isteklerinin yerine getirilmesinde önemli rol oynamaktadır (Kim ve Han, 2013). Bireylerin birçok spora katılma isteğini yerine getirebilen spor merkezlerinin işlevleri ve rolleri şu anda güçlendirilmektedir. Özellikle spor merkezleri sa- 
dece bireylerin sağlığında değil, aynı zamanda bireylerin spor aktiviteleri yoluyla kendini gerçekleştirmeyi deneyimlemesi için önemli roller oynamakta ve sosyal sporun gelişmesine büyük ölçüde katkıda bulunmaktadır ( $\mathrm{Im}, \mathrm{O}$ ve Kim, 2015).

Müşteri beklentisi, gelecekteki bir durumun tahmini ve özellikle de bilinen bir ihtiyacın karşılanmasından sonra elde edilecek olası fayda olarak tanımlanır. Başka bir deyişle, beklenti, spor tesisleri ve işletmelerde müşteri memnuniyetini ve sürekliliğini sağlamanın önemli bir belirleyicisi olarak görülmektedir (Yu vd., 2014). Beklenti kavramı öznel olduğu için çoğu zaman bunu tanımlamak zor. Bu nedenle, beklentiler bazen doğrudan ortaya çıkar, bazıları keşfedilmeyi gerekir (Silvestro, 2002). Müşteri beklentilerinin işletmeler tarafından ele alınması ve bu değişimlerin demografik, sosyo-ekonomik ve kültürel boyutlarda analiz edilmesi önem kazanmaktadır. Çünkü bir spor merkezinin başarılı olabilmesi için müşteri beklentilerinin anlaşılması ve karşılanması beklenmektedir.

Spor hizmetlerinde kalitenin ölçülmesi oldukça tartışmalı bir konudur (Theodorakis, vd., 2014;). İlk hizmet kalitesi ölçekleri arasında Parasuraman, Berry ve Zeithaml'ın (1988) beş boyutlu SERVQUAL enstrümanı, Brady ve Cronin'in üç boyutlu modeli (2001) ve Gronroos'un (2005) iki boyutlu modeli yer almaktadır. Spor ve fitness merkezleri alanında araştırmacılar hem ilişkisel hem de fiziksel kalite ölçülerini ve sonuçları içeren ölçekleri kullanma eğiliminde olmuşlardır (Theodorakis ve ark., 2014).

Araştırmacılar, müşteriler tarafından yapılan kalite algilamaları, onların hizmet kalitesini nasıl değerlendirdiği ile ilgili temel soruları yanıtlamaya çalışırlar (Lentell, 2000). Bu soruların yanıtları yöneticiler ve araştırmacılar için çok önemlidir, zira bu bilgi, pazarlama çabalarını müşterileri için önemli olan alanlara odaklamalarını sağlayacaktır (Dhurup, Singh ve Surujlal, 2006). Ayrıca, bu tür bilgiler, kuruluşların rekabet avantajı ve farklılaşmasını nasıl sağabilecekleri konusunda rehberlik sağlamaktadır (Metha, Lalwani ve Han, 2000). Hizmet kuruluşları müşteri algıları hakkında bilgi sahibi olmak hayati önem taşımaktadır. Çünkü spor sektöründe çok çeşitli faktörlerden etkilenir.

Yüksek performanslı programların sunulmasında bu faktörler programın sunumu, personelin tutumu ve etkileşimi, tesisler ve programla ilişkili diğer kaynakların uygulanabilirliği ve programın uygulanabilirliğini içerebilir (Dhurup ve ark., 2006). Hizmet kalitesi üzerine günümüze kadar gelen lite- 
ratür, bir hizmeti fiziksel bir üründen ayıran dört özelliğin, yani soyutluk, heterojenlik, ayrılmazlık ve bozulabilirlik olduğunu göstermektedir. Ürünlerin çoğundan farklı olarak spor programları ile ilişkili hizmetler elle tutulamaz ve sübjektiftir (Zeithaml ve Bitner, 2000). Ayrıca, üretilen, satılan ve tüketilen malların aksine, spor programları önce satılır, sonra aynı anda üretilir ve tüketilir. Spor programları içinde yönetici ve antrenör gibi birkaç farklı tedarikçi olduğundan, hizmetlerin kalite algılarımaları tutarlılık ve öngörülebilirlik açısından farklılık gösterebilir. Yani kişiden kişiye göre değişkendir (Kotler, 2003). Çoğu durumda spor programlar aracılığıyla sağlanan hizmetler depolanamaz. Bu nedenle, programın yöneticileri hizmetlerinin ve performanslarının envanterini geliştiremez ve saklayamazlar (Du Plessis, Rousseau \& Blem, 1995). Katılımc1, katılım deneyiminden sonra hizmet kalitesi algısı ve memnuniyet düzeyi geliştirir. Son derece memnun bir katılımcı belirli bir hizmete bağlı olma eğilimindedir ve sonunda sadık bir müş̧teri olur (Brady \& Robertson, 2001). Dolayısıyla, hizmetlerin kalitesi ile işletme ve personellerin performansının ölçülmesinde müşteri memnuniyeti en önemli enstrümanlar arasindadir.

Literatürde, spor ve özel spor merkezlerindeki müşterilerin hizmet kalitesi algılarını ölçmek için çeşitli yaklaşımlar sunan çalışmalar mevcuttur (İslamoğlu, 2019; Aras, Çimen ve Bal, 2019; Kaya, Yücedağ, Aşıkkutlu ve Keskin, 2019; Fernandez, Carrion ve Ruitz, 2012; Theodorakis ve diğerleri, 2014;). Spor işletmeleri, varlıklarını sürdürmek ve müşterilerin sporla ilgili beklentilerini ve ihtiyaçlarını karşılamak için en uygun fiyat ve zamanda hizmet sunma eğilimindedir. Bu nedenle, spor hizmetlerinin müşteri gereksinimlerini karşılayabilmesini sağlamak için müşteri talep ve beklentilerini öğrenmek önemli bir bileşendir (Howard ve Crompton, 1980). Bu çalışma, spor merkezlerinde müşteri beklentilerini belirlemek ve hizmet kalitesi algılarını araştırmak ve bu işletmelerde ne tür hizmetlerin sunulması gerektiğini belirlemek açısından önemlidir. Bu çalışmada, spor merkezi üyelerinin beklentilerini ve algılanan hizmet kalitesi düzeylerini öngören değişkenlerin araştırılması amaçlanmıştır. Araştırma bulgularının, kamu ve özel spor merkezlerinde hizmet kalitesini iyileştirmek için ilgili somut kanıtlarla birlikte öneriler getireceği düşünülmektedir. Ayrıca, bu çalışma, müşteri memnuniyeti ve beklentisinin gelecekte spor merkezi tercihlerini ne ölçüde belirlediğini tahmin etmemize yardımcı olmayı amaçlamaktadır. 


\section{Materyal ve Metot}

\section{Araştırma Grubu}

Bu araştırmada, araştırma grubu, Zeytinburnu Belediyesi tarafından işletilen 2 yüzme havuzu ve 2 spor salonunda aktif olarak üyeliği devam eden kişiler arasından gönüllü örneklem yöntemi ile oluşturulmuştur. Bu yöntemle araştırmaya 372 kişi katılmış olup katılımcıların cinsiyete göre dağılımı incelendiğinde; kadınların oranı \%64, erkeklerin oranı ise \%36'dır. Yaş gruplarına göre dağılım incelendiğinde; 18-30 yaş grubu kişilerin oranı \%23,4, 31-40 yaş grubu kişilerin oranı \%38,7 olup 41-50 yaş grubu kişilerin oranı \%18,3'tür. 5160 yaş grubu kişilerin oranı \%17,2 olup 60+ yaş grubu kişilerin oranı \%2,4'tür. Eğitim durumuna göre dağılım incelendiğinde; ilköğretim mezunları oranı $\% 20,4, \mathrm{i}$ lise mezunları oranı $\% 39,8$, ön lisans mezunları oranı $\% 25,5$ olup lisans mezunları oranı \%14,2'dir. Gelir grupları incelendiğinde katılımcıların \%61,6'sı 2000-3000 TL, \%29,6'sı 3000-4000 TL, \%5,9'u 5000-6000 TL, \%3'ü ise 6000-7000 gelir grubundadır. Spor yapılan gün sayılarına göre dağılım incelendiğinde; haftada 1 gün spor yapanların oranı \%11, 2 gün spor yapanların oranı \%35,8, 3 gün spor yapanların oranı \%35,8 olup 4 gün spor yapanların oranı \%4,6, 5 gün spor yapanların oranı ise \%12,9'dur. Spor yılına göre dağ1lım incelendiğinde; 1-2 yıldır spor yapanların oranı \%20,7, 3-4 yıldır spor yapanların oran1 \%19,4, 4-5 gün spor yapanların oran1 \%26,1 olup 5-6 gün spor yapanların oranı $\% 16,9,7-8$ gün spor yapanların oranı $\% 16,9^{\prime}$ dur.

\section{Veri Toplama Araçlam}

Araştırmada veri toplama aracı olarak ilk bölümü katılımcıların yaş, cinsiyet, eğitim durumu, gelir, spor yaptıkları gün ve yıl sayıları ile ilgili sorular oluşturmuştur. İkinci bölümde ise katılımcıların yerel yönetim spor tesisleri hizmet algılarını tespit edebilmek amacıyla Köşker Demir ve Çimen (2012) tarafından geçerliliği ve güvenirliliği yapılan, "Rekreasyonel Spor Hizmetleri Kalite Ölçeği” kullanılmıştır. Ölçek 10 alt boyutlu olup 38 maddeden oluşmaktadır. Bu alt boyutlar, "program çeşitliliği" (3 madde), "çalışma zamanı" (2 madde), "bilgi" (4 madde), "müşteri-çalışan etkileşimi" (6 madde), "müşteriler arası etkileşim" (2 madde), "fiziksel değişim" (5 madde), "birleşim değeri" (2 madde), sosyalleşme (3 madde), "tasarım" (5 madde), "malzeme" (4 madde)'dir. 


\section{Verilerin Analizi}

Verilerin analizinde bağımsız gruplarda t testi, tek yönlü varyans analizi, ölçeğin güvenilirlik düzeyinin belirlenmesi için güvenilirlik analizi yapılmış ve chronbach alfa iç tutarlık testi kullanılmıştır.

\section{Bulgular}

\section{Rekreasyonel Spor Hizmetleri Kalite Ölçeğinin Cinsiyete Göre Değişimi}

Rekreasyonel spor hizmetleri kalite ölçeğinin cinsiyete göre ortalamaları ve bu ortalamalar arasındaki farkın anlamlı olup olmadığı bağımsız gruplarda $t$ testi ile incelenmiştir.

\begin{tabular}{|c|c|c|c|c|c|c|}
\hline & & $\mathrm{N}$ & Ortalama & Std Sapma & $\mathrm{t}$ & $\mathrm{p}$ \\
\hline \multirow{2}{*}{ Toplam Kalite } & Kadın & 238 & 5,15 & 2,19 & \multirow{2}{*}{1,238} & \multirow{2}{*}{0,217} \\
\hline & Erkek & 134 & 4,88 & 1,84 & & \\
\hline \multirow{2}{*}{ Müşteri-Çalışan Etkileşimi } & Kadın & 238 & 5,19 & 2,20 & \multirow{2}{*}{$-0,490$} & \multirow{2}{*}{0,625} \\
\hline & Erkek & 134 & 5,29 & 1,63 & & \\
\hline \multirow{2}{*}{ Tasarım } & Kadın & 238 & 5,12 & 2,23 & \multirow{2}{*}{$-0,009$} & \multirow{2}{*}{0,993} \\
\hline & Erkek & 134 & 5,12 & 1,64 & & \\
\hline \multirow{2}{*}{ Fiziksel Değişim } & Kadın & 238 & 5,23 & 2,25 & \multirow{2}{*}{1,868} & \multirow{2}{*}{0,063} \\
\hline & Erkek & 134 & 4,79 & 2,15 & & \\
\hline \multirow{2}{*}{ Bilgi } & Kadın & 238 & 5,18 & 2,21 & \multirow{2}{*}{2,487} & \multirow{2}{*}{$0,013^{*}$} \\
\hline & Erkek & 134 & 4,60 & 2,00 & & \\
\hline \multirow{2}{*}{ Sosyalleşme } & Kadın & 238 & 5,20 & 2,16 & \multirow{2}{*}{1,633} & \multirow{2}{*}{0,103} \\
\hline & Erkek & 134 & 4,82 & 2,11 & & \\
\hline \multirow{2}{*}{ Malzeme } & Kadın & 238 & 5,10 & 2,19 & \multirow{2}{*}{0,329} & \multirow{2}{*}{0,742} \\
\hline & Erkek & 134 & 5,03 & 1,61 & & \\
\hline \multirow{2}{*}{ Program Çeşitliliği } & Kadın & 238 & 5,07 & 2,34 & \multirow{2}{*}{2,057} & \multirow{2}{*}{$0,040^{*}$} \\
\hline & Erkek & 134 & 4,57 & 2,14 & & \\
\hline \multirow{2}{*}{ Birleşme Değeri } & Kadın & 238 & 5,15 & 2,14 & \multirow{2}{*}{1,086} & \multirow{2}{*}{0,278} \\
\hline & Erkek & 134 & 4,90 & 2,00 & & \\
\hline \multirow{2}{*}{ Müşteriler arası Etkileşim } & Kadın & 238 & 5,07 & 2,09 & \multirow{2}{*}{0,151} & \multirow{2}{*}{0,880} \\
\hline & Erkek & 134 & 5,04 & 1,82 & & \\
\hline \multirow{2}{*}{ Çalışma Zamanı } & Kadın & 238 & 5,11 & 2,18 & \multirow{2}{*}{4,687} & \multirow{2}{*}{$0,000^{*}$} \\
\hline & Erkek & 134 & 4,03 & 2,04 & & \\
\hline
\end{tabular}

${ }^{*} \mathrm{p}<0,05$

Bağımsız gruplarda $t$ testi sonuçlarına göre; bilgi, program çeşitliliği ve çalışma zamanı alt boyutları cinsiyete göre anlamlı düzeyde farklılık göstermektedir $(p<0,05)$. Kadınların bilgi, program çeşitliliği ve çalışma zamanı alt boyutları düzeyi erkeklerden anlamlı derecede daha yüksektir. 


\section{Rekreasyonel Spor Hizmetleri Kalite Ölçeğinin Yaşa Göre Değişimi}

Rekreasyonel spor hizmetleri kalite ölçeğinin yaşa göre ortalamaları ve bu ortalamalar arasındaki farkın anlamlı olup olmadığ tek yönlü varyans analizi ile incelenmiştir.

\begin{tabular}{|c|c|c|c|c|c|c|}
\hline & & $\mathrm{N}$ & Ortalama & Std. Sapma & $\mathrm{F}$ & $\mathrm{p}$ \\
\hline \multirow{6}{*}{ Toplam Kalite } & $18-30$ & 87 & 6,05 & 1,52 & \multirow{6}{*}{29,817} & \multirow{6}{*}{0,000} \\
\hline & $31-40$ & 144 & 4,21 & 2,13 & & \\
\hline & $41-50$ & 68 & 4,08 & 2,29 & & \\
\hline & $51-60$ & 64 & 6,43 & 0,09 & & \\
\hline & $60+$ & 9 & 6,40 & 0,08 & & \\
\hline & Toplam & 372 & 5,06 & 2,07 & & \\
\hline \multirow{6}{*}{ Müşteri-Çalışan Etkileşimi } & $18-30$ & 87 & 6,22 & 1,60 & \multirow{6}{*}{33,565} & \multirow{6}{*}{0,000} \\
\hline & $31-40$ & 144 & 4,41 & 1,93 & & \\
\hline & $41-50$ & 68 & 4,18 & 2,25 & & \\
\hline & $51-60$ & 64 & 6,64 & 0,38 & & \\
\hline & $60+$ & 9 & 6,57 & 0,25 & & \\
\hline & Toplam & 372 & 5,23 & 2,01 & & \\
\hline \multirow{6}{*}{ Tasarım } & $18-30$ & 87 & 6,18 & 1,58 & \multirow{6}{*}{27,842} & \multirow{6}{*}{0,000} \\
\hline & $31-40$ & 144 & 4,32 & 2,08 & & \\
\hline & $41-50$ & 68 & 4,18 & 2,25 & & \\
\hline & $51-60$ & 64 & 6,32 & 0,41 & & \\
\hline & $60+$ & 9 & 6,44 & 0,26 & & \\
\hline & Toplam & 372 & 5,12 & 2,04 & & \\
\hline \multirow{6}{*}{ Fiziksel Değişim } & $18-30$ & 87 & 6,18 & 1,58 & \multirow{6}{*}{$-31,678$} & \multirow{6}{*}{0,000} \\
\hline & $31-40$ & 144 & 4,12 & 2,34 & & \\
\hline & $41-50$ & 68 & 4,08 & 2,30 & & \\
\hline & $51-60$ & 64 & 6,59 & 0,20 & & \\
\hline & $60+$ & 9 & 6,47 & 0,22 & & \\
\hline & Toplam & 372 & 5,07 & 2,22 & & \\
\hline \multirow{6}{*}{ Bilgi } & $18-30$ & 87 & 5,93 & 1,56 & \multirow{6}{*}{29,881} & \multirow{6}{*}{0,000} \\
\hline & $31-40$ & 144 & 4,12 & 2,19 & & \\
\hline & $41-50$ & 68 & 3,93 & 2,41 & & \\
\hline & $51-60$ & 64 & 6,51 & 0,45 & & \\
\hline & $60+$ & 9 & 6,22 & 0,48 & & \\
\hline & Toplam & 372 & 4,97 & 2,15 & & \\
\hline \multirow{6}{*}{ Sosyalleşme } & $18-30$ & 87 & 6,15 & 1,57 & \multirow{6}{*}{31,888} & \multirow{6}{*}{0,000} \\
\hline & $31-40$ & 144 & 4,10 & 2,24 & & \\
\hline & $41-50$ & 68 & 4,18 & 2,25 & & \\
\hline & $51-60$ & 64 & 6,49 & 0,17 & & \\
\hline & $60+$ & 9 & 6,63 & 0,11 & & \\
\hline & Toplam & 372 & 5,07 & 2,15 & & \\
\hline \multirow{4}{*}{ Malzeme } & $18-30$ & 87 & 6,09 & 1,54 & \multirow{4}{*}{27,360} & \multirow{4}{*}{0,000} \\
\hline & $31-40$ & 144 & 4,28 & 2,04 & & \\
\hline & $41-50$ & 68 & 4,18 & 2,25 & & \\
\hline & $51-60$ & 64 & 6,31 & 0,22 & & \\
\hline
\end{tabular}




\begin{tabular}{|c|c|c|c|c|c|c|}
\hline & $60+$ & 9 & 6,08 & 0,18 & & \\
\hline & Toplam & 372 & 5,08 & 2,00 & & \\
\hline \multirow{6}{*}{ Program Çeşitliliği } & $18-30$ & 87 & 5,87 & 1,50 & \multirow{6}{*}{26,595} & \multirow{6}{*}{0,000} \\
\hline & $31-40$ & 144 & 4,03 & 2,53 & & \\
\hline & $41-50$ & 68 & 3,84 & 2,38 & & \\
\hline & $51-60$ & 64 & 6,38 & 0,41 & & \\
\hline & $60+$ & 9 & 6,59 & 0,22 & & \\
\hline & Toplam & 372 & 4,89 & 2,28 & & \\
\hline \multirow{6}{*}{ Birleşme Değeri } & $18-30$ & 87 & 6,22 & 1,60 & \multirow{6}{*}{27,106} & \multirow{6}{*}{0,000} \\
\hline & $31-40$ & 144 & 4,28 & 2,15 & & \\
\hline & $41-50$ & 68 & 4,01 & 2,35 & & \\
\hline & $51-60$ & 64 & 6,17 & 0,26 & & \\
\hline & $60+$ & 9 & 6,22 & 0,24 & & \\
\hline & Toplam & 372 & 5,06 & 2,09 & & \\
\hline \multirow{6}{*}{ Müşterilerarası Etkileşim } & $18-30$ & 87 & 6,01 & 1,53 & \multirow{6}{*}{25,044} & \multirow{6}{*}{0,000} \\
\hline & $31-40$ & 144 & 4,31 & 2,05 & & \\
\hline & $41-50$ & 68 & 4,18 & 2,25 & & \\
\hline & $51-60$ & 64 & 6,21 & 0,46 & & \\
\hline & $60+$ & 9 & 6,50 & 0,50 & & \\
\hline & Toplam & 372 & 5,06 & 1,99 & & \\
\hline \multirow{6}{*}{ Çalışma Zamanı } & $18-30$ & 87 & 5,13 & 1,79 & \multirow{6}{*}{18,894} & \multirow{6}{*}{0,000} \\
\hline & $31-40$ & 144 & 4,05 & 2,34 & & \\
\hline & $41-50$ & 68 & 3,93 & 2,41 & & \\
\hline & $51-60$ & 64 & 6,34 & 0,64 & & \\
\hline & $60+$ & 9 & 6,00 & 0,61 & & \\
\hline & Toplam & 372 & 4,72 & 2,19 & & \\
\hline
\end{tabular}

Tek yönlü varyans analizi sonuçlarına göre tüm alt boyutlar yaşa göre anlamlı farklılık göstermektedir $(\mathrm{p}<0,05)$. Farklılığın hangi gruptan kaynaklandığını tespit etmek amacıyla yapılan TUKEY testi sonuçlarına göre

Toplam kalite algısı, müşteri çalışan etkileşimi, tasarım, fiziksel değişim, bilgi, sosyalleşme, malzeme, program çeşitliliği, birleşme değeri, müşteriler arası etkileşim ve çalışma zamanı alt boyutları için $18-30$, 51-60 ve 60+ yaş grubu kişilerin ortalaması 31-40 ve 41-50 yaş grubu kişilerden anlamlı derecede daha yüksektir.

\section{Rekreasyonel Spor Hizmetleri Kalite Ölçeğinin Haftalık Spor Günü Sayısına Göre Değişimi}

Rekreasyonel spor hizmetleri kalite ölçeğinin haftalık spor günü sayısına göre ortalamaları ve bu ortalamalar arasındaki farkın anlamlı olup olmadığı tek yönlü varyans analizi ile incelenmiştir. 
Arif Çetin - Ayşe Demir

\begin{tabular}{|c|c|c|c|c|c|c|}
\hline & & $\mathrm{N}$ & Ortalama & Std. Sapma & $\mathrm{F}$ & $\mathrm{p}$ \\
\hline \multirow[t]{6}{*}{ Toplam Kalite } & 1 & 41 & 4,53 & 2,72 & \multirow{6}{*}{22,447} & \multirow{6}{*}{$0,000^{*}$} \\
\hline & 2 & 133 & 4,92 & 2,15 & & \\
\hline & 3 & 133 & 6,02 & 1,20 & & \\
\hline & 4 & 17 & 2,19 & 0,00 & & \\
\hline & 5 & 48 & 4,20 & 2,00 & & \\
\hline & Toplam & 372 & 5,06 & 2,07 & & \\
\hline \multirow[t]{6}{*}{ Müşteri-Çalışan Etkileşimi } & 1 & 41 & 4,76 & 2,89 & \multirow{6}{*}{9,766} & \multirow{6}{*}{$0,000^{*}$} \\
\hline & 2 & 133 & 5,12 & 2,25 & & \\
\hline & 3 & 133 & 5,95 & 1,18 & & \\
\hline & 4 & 17 & 4,00 & 0,00 & & \\
\hline & 5 & 48 & 4,33 & 1,91 & & \\
\hline & Toplam & 372 & 5,23 & 2,01 & & \\
\hline \multirow[t]{6}{*}{ Tasarım } & 1 & 41 & 4,69 & 2,84 & \multirow{6}{*}{16,538} & \multirow{6}{*}{$0,000^{*}$} \\
\hline & 2 & 133 & 4,77 & 2,16 & & \\
\hline & 3 & 133 & 6,11 & 1,21 & & \\
\hline & 4 & 17 & 3,40 & 0,00 & & \\
\hline & 5 & 48 & 4,33 & 1,91 & & \\
\hline & Toplam & 372 & 5,12 & 2,04 & & \\
\hline \multirow[t]{6}{*}{ Fiziksel Değişim } & 1 & 41 & 4,63 & 2,80 & \multirow{6}{*}{31,748} & \multirow{6}{*}{$0,000^{*}$} \\
\hline & 2 & 133 & 5,02 & 2,25 & & \\
\hline & 3 & 133 & 6,11 & 1,18 & & \\
\hline & 4 & 17 & 1,00 & 0,00 & & \\
\hline & 5 & 48 & 4,19 & 2,01 & & \\
\hline & Toplam & 372 & 5,07 & 2,22 & & \\
\hline \multirow[t]{6}{*}{ Bilgi } & 1 & 41 & 4,66 & 2,82 & \multirow{6}{*}{26,224} & \multirow{6}{*}{$0,000^{*}$} \\
\hline & 2 & 133 & 4,89 & 2,14 & & \\
\hline & 3 & 133 & 5,94 & 1,19 & & \\
\hline & 4 & 17 & 1,50 & 0,00 & & \\
\hline & 5 & 48 & 3,98 & 2,20 & & \\
\hline & Toplam & 372 & 4,97 & 2,15 & & \\
\hline \multirow[t]{6}{*}{ Sosyalleşme } & 1 & 41 & 4,71 & 2,85 & \multirow{6}{*}{32,592} & \multirow{6}{*}{$0,000^{*}$} \\
\hline & 2 & 133 & 4,95 & 2,10 & & \\
\hline & 3 & 133 & 6,08 & 1,18 & & \\
\hline & 4 & 17 & 1,00 & 0,00 & & \\
\hline & 5 & 48 & 4,33 & 1,91 & & \\
\hline & Toplam & 372 & 5,07 & 2,15 & & \\
\hline \multirow[t]{6}{*}{ Malzeme } & 1 & 41 & 4,41 & 2,63 & \multirow{6}{*}{15,853} & \\
\hline & 2 & 133 & 4,87 & 2,20 & & \\
\hline & 3 & 133 & 5,99 & 1,17 & & $0 \Omega 00$ * \\
\hline & 4 & 17 & 3,25 & 0,00 & & $0,000^{\circ}$ \\
\hline & 5 & 48 & 4,33 & 1,91 & & \\
\hline & Toplam & 372 & 5,08 & 2,00 & & \\
\hline Program Çeşitliliği & 1 & 41 & 4,06 & 2,35 & & \\
\hline & 2 & 133 & 4,84 & 2,32 & & \\
\hline & 3 & 133 & 6,03 & 1,44 & & $\Omega 000^{*}$ \\
\hline & 4 & 17 & 1,00 & 0,00 & $31,8 / 9$ & $0,000^{x}$ \\
\hline & 5 & 48 & 3,98 & 2,20 & & \\
\hline & Toplam & 372 & 4,89 & 2,28 & & \\
\hline Birleşme Değeri & 1 & 41 & 4,71 & 2,85 & 24.107 & $0000^{*}$ \\
\hline & 2 & 133 & 4,92 & 2,07 & 24,107 & $0,000^{\circ}$ \\
\hline
\end{tabular}




\begin{tabular}{|c|c|c|c|c|c|c|}
\hline & 3 & 133 & 6,04 & 1,20 & & \\
\hline & 4 & 17 & 2,00 & 0,00 & & \\
\hline & 5 & 48 & 4,10 & 2,09 & & \\
\hline & Toplam & 372 & 5,06 & 2,09 & & \\
\hline \multirow[t]{6}{*}{ Müşterilerarası Etkileşim } & 1 & 41 & 4,02 & 2,33 & \multirow{6}{*}{23,619} & \multirow{6}{*}{$0,000^{*}$} \\
\hline & 2 & 133 & 5,02 & 2,14 & & \\
\hline & 3 & 133 & 6,01 & 1,16 & & \\
\hline & 4 & 17 & 2,50 & 0,00 & & \\
\hline & 5 & 48 & 4,33 & 1,91 & & \\
\hline & Toplam & 372 & 5,06 & 1,99 & & \\
\hline \multirow[t]{6}{*}{ Çalışma Zamanı } & 1 & 41 & 3,85 & 2,19 & \multirow{6}{*}{36,614} & \multirow{6}{*}{$0,000^{*}$} \\
\hline & 2 & 133 & 4,56 & 2,14 & & \\
\hline & 3 & 133 & 5,95 & 1,32 & & \\
\hline & 4 & 17 & 1,00 & 0,00 & & \\
\hline & 5 & 48 & 3,82 & 2,28 & & \\
\hline & Toplam & 372 & 4,72 & 2,19 & & \\
\hline
\end{tabular}

${ }^{*} \mathrm{p}<0,05$

Tek yönlü varyans analizi sonuçlarına göre tüm alt boyutlar haftalık spor günü sayısına göre anlamlı farklılık göstermektedir $(\mathrm{p}<0,05)$. Farklılığın hangi gruptan kaynaklandığııı tespit etmek amacıyla yapılan TUKEY testi sonuçlarına göre;

Toplam kalite için 2 ve 3 gün spor yapanların algı düzeyi 4 ve 5 gün spor yapanlardan, 1 ve 5 gün spor yapanların algı düzeyi 4 gün spor yapanlardan anlamlı derecede daha yüksektir.

Müşteri çalışan etkileşimi için 3 gün spor yapanların ortalaması diğger gruplarında hepsinden anlamlı derecede daha yüksektir. Ek olarak 2 gün spor yapanların algı düzeyi 4 ve 5 gün yapanlardan anlamlı derecede daha yüksektir.

Tasarım alt boyutu için, 3 gün spor yapanların algı düzeyi diğer tüm gruplardan anlamlı derecede daha yüksektir. Ek olarak 1-2 gün spor yapanların ortalaması 4 gün spor yapanlardan anlamlı derecede daha yüksektir.

Fiziksel değişim için, 3 gün spor yapanların algı düzeyi diğer tüm gruplardan anlamlı derecede daha yüksektir. Ek olarak, 2 gün spor yapanların ortalaması 4 ve 5 gün yapanlardan, 1 ve 5 gün yapanların algı düzeyi ise 4 gün yapanlardan anlamlı derecede daha yüksektir.

Bilgi ve sosyalleşme alt boyutları için 3 gün spor yapanların algı düzeyi diğer tüm gruplardan anlamlı derecede daha yüksektir. Ek olarak 2 gün spor yapanların ortalaması 4 ve 5 gün spor yapanlardan, 1 ve gün spor yapanların algı düzeyi de 4 gün spor yapanlardan anlamlı derecede daha yüksektir. 
Malzeme alt boyutu için 3 gün spor yapanların algı düzeyi diğer tüm gruplardan anlamlı derecede daha yüksektir. Ek olarak, 1,2 ve 5 gün spor yapanların algı düzeyi 4 gün spor yapanlardan anlamlı derecede daha yüksektir.

Program çeşitliliği alt boyutu için 3 gün spor yapanların algı düzeyi diğer tüm gruplardan anlamlı derecede daha yüksektir. Ek olarak 2 gün spor yapanların ortalaması 1,4 ve 5 gün yapanlardan, 1 gün spor yapanların algı düzeyi 4 gün spor yapanlardan anlamlı derecede daha yüksektir.

Birleşme değeri alt boyutu için 3 gün spor yapanların algi düzeyi diğer tüm gruplardan anlamlı derecede daha yüksektir. Ek olarak 2 gün spor yapanların ortalaması 4 ve 5 gün yapanlardan, 1 gün spor yapanların algı düzeyi 4 gün spor yapanlardan anlamlı derecede daha yüksektir.

Müşteriler arası etkileşim ve çalışma zamanı alt boyutları için 3 gün spor yapanların algı düzeyi diğer tüm gruplardan anlamlı derecede daha yüksektir. Ek olarak 2 gün spor yapanların ortalaması 1,4 ve 5 gün yapanlardan, 1 ve 5 gün spor yapanların algı düzeyi 4 gün spor yapanlardan anlamlı derecede daha yüksektir.

\section{Rekreasyonel Spor Hizmetleri Kalite Ölçeğinin Spor Yılına Göre Değişimi}

Rekreasyonel spor hizmetleri kalite ölçeğinin spor yılına göre ortalamaları ve bu ortalamalar arasındaki farkın anlamlı olup olmadığı tek yönlü varyans analizi ile incelenmiştir.

\begin{tabular}{|c|c|c|c|c|c|c|}
\hline & & $\mathrm{N}$ & Ortalama & Std.Sapma & $\mathrm{F}$ & $\mathrm{p}$ \\
\hline \multirow[t]{6}{*}{ Toplam Kalite } & $1-2$ & 77 & 4,90 & 2,43 & \multirow{6}{*}{15,075} & \multirow{6}{*}{$0,000^{*}$} \\
\hline & $3-4$ & 72 & 5,82 & 1,59 & & \\
\hline & $4-5$ & 97 & 4,79 & 2,07 & & \\
\hline & $5-6$ & 63 & 6,08 & 0,79 & & \\
\hline & $7-8$ & 63 & 3,75 & 2,18 & & \\
\hline & Toplam & 372 & 5,06 & 2,07 & & \\
\hline \multirow[t]{6}{*}{ Müşteri-Çalışan Etkileşimi } & $1-2$ & 77 & 5,05 & 2,53 & \multirow{6}{*}{11,244} & \multirow{6}{*}{$0,000^{*}$} \\
\hline & $3-4$ & 72 & 5,94 & 1,66 & & \\
\hline & $4-5$ & 97 & 4,87 & 2,00 & & \\
\hline & $5-6$ & 63 & 6,14 & 0,77 & & \\
\hline & $7-8$ & 63 & 4,25 & 1,95 & & \\
\hline & Toplam & 372 & 5,23 & 2,01 & & \\
\hline \multirow[t]{6}{*}{ Tasarım } & $1-2$ & 77 & 5,05 & 2,53 & \multirow{6}{*}{10,142} & \multirow{6}{*}{$0,000^{*}$} \\
\hline & $3-4$ & 72 & 5,63 & 1,55 & & \\
\hline & $4-5$ & 97 & 4,84 & 2,14 & & \\
\hline & $5-6$ & 63 & 6,10 & 0,83 & & \\
\hline & $7-8$ & 63 & 4,09 & 1,99 & & \\
\hline & Toplam & 372 & 5,12 & 2,04 & & \\
\hline
\end{tabular}


Rekreasyonel Spor Tesisleri Üyelerinin Algılanan Hizmet Kalitesi Düzeylerinin İncelenmesi

\begin{tabular}{|c|c|c|c|c|c|c|}
\hline \multirow[t]{6}{*}{ Fiziksel Değişim } & $1-2$ & 77 & 5,05 & 2,53 & \multirow{6}{*}{18,170} & \multirow{6}{*}{$0,000^{*}$} \\
\hline & $3-4$ & 72 & 5,88 & 1,62 & & \\
\hline & $4-5$ & 97 & 4,81 & 2,14 & & \\
\hline & $5-6$ & 63 & 6,21 & 0,79 & & \\
\hline & $7-8$ & 63 & 3,44 & 2,45 & & \\
\hline & Toplam & 372 & 5,07 & 2,22 & & \\
\hline \multirow[t]{6}{*}{ Bilgi } & $1-2$ & 77 & 4,72 & 2,35 & \multirow{6}{*}{17,331} & \multirow{6}{*}{$0,000^{*}$} \\
\hline & $3-4$ & 72 & 5,99 & 1,68 & & \\
\hline & $4-5$ & 97 & 4,66 & 2,18 & & \\
\hline & $5-6$ & 63 & 5,97 & 0,77 & & \\
\hline & $7-8$ & 63 & 3,58 & 2,32 & & \\
\hline & Toplam & 372 & 4,97 & 2,15 & & \\
\hline \multirow[t]{6}{*}{ Sosyalleşme } & $1-2$ & 77 & 5,05 & 2,53 & \multirow{6}{*}{$-16,542$} & \multirow{6}{*}{$0,000^{*}$} \\
\hline & $3-4$ & 72 & 5,74 & 1,56 & & \\
\hline & $4-5$ & 97 & 4,98 & 1,96 & & \\
\hline & $5-6$ & 63 & 6,06 & 0,88 & & \\
\hline & $7-8$ & 63 & 3,44 & 2,45 & & \\
\hline & Toplam & 372 & 5,07 & 2,15 & & \\
\hline \multirow[t]{6}{*}{ Malzeme } & $1-2$ & 77 & 4,96 & 2,47 & \multirow{6}{*}{$-11,515$} & \multirow{6}{*}{$0,000^{*}$} \\
\hline & $3-4$ & 72 & 5,82 & 1,59 & & \\
\hline & $4-5$ & 97 & 4,73 & 2,01 & & \\
\hline & $5-6$ & 63 & 5,94 & 0,79 & & \\
\hline & $7-8$ & 63 & 4,05 & 2,01 & & \\
\hline & Toplam & 372 & 5,08 & 2,00 & & \\
\hline \multirow[t]{6}{*}{ Program Çeşitliliği } & $1-2$ & 77 & 4,66 & 2,27 & \multirow{6}{*}{ - 19,402} & \multirow{6}{*}{$0,000^{*}$} \\
\hline & $3-4$ & 72 & 5,90 & 1,63 & & \\
\hline & $4-5$ & 97 & 4,57 & 2,44 & & \\
\hline & $5-6$ & 63 & 6,10 & 0,94 & & \\
\hline & $7-8$ & 63 & 3,31 & 2,49 & & \\
\hline & Toplam & 372 & 4,89 & 2,28 & & \\
\hline \multirow[t]{6}{*}{ Birleşme Değeri } & $1-2$ & 77 & 5,05 & 2,53 & \multirow{6}{*}{ - 15,078} & \multirow{6}{*}{$0,000^{*}$} \\
\hline & $3-4$ & 72 & 5,68 & 1,55 & & \\
\hline & $4-5$ & 97 & 4,75 & 2,03 & & \\
\hline & $5-6$ & 63 & 6,17 & 0,77 & & \\
\hline & $7-8$ & 63 & 3,71 & 2,21 & & \\
\hline & Toplam & 372 & 5,06 & 2,09 & & \\
\hline \multirow[t]{6}{*}{ Müşterilerarası Etkileşim } & $1-2$ & 77 & 4,87 & 2,42 & \multirow{6}{*}{ - 15,098} & \multirow{6}{*}{$0,000^{*}$} \\
\hline & $3-4$ & 72 & 5,58 & 1,48 & & \\
\hline & $4-5$ & 97 & 4,85 & 1,90 & & \\
\hline & $5-6$ & 63 & 6,25 & 0,79 & & \\
\hline & $7-8$ & 63 & 3,85 & 2,11 & & \\
\hline & Toplam & 372 & 5,06 & 1,99 & & \\
\hline \multirow[t]{6}{*}{ Çalışma Zamanı } & $1-2$ & 77 & 3,80 & 2,17 & & \\
\hline & $3-4$ & 72 & 5,91 & 1,64 & & \\
\hline & $4-5$ & 97 & 4,75 & 2,16 & & $0000^{*}$ \\
\hline & $5-6$ & 63 & 5,82 & 0,81 & 23,464 & $0,000^{*}$ \\
\hline & $7-8$ & 63 & 3,34 & 2,48 & & \\
\hline & Toplam & 372 & 4,72 & 2,19 & & \\
\hline
\end{tabular}

${ }^{*} \mathrm{p}<0,05$ 
Tek yönlü varyans analizi sonuçlarına göre tüm alt boyutlar haftalık spor günü sayısına göre anlamlı farklılık göstermektedir $(\mathrm{p}<0,05)$. Farklılığın hangi gruptan kaynaklandığını tespit etmek amaciyla yapılan TUKEY testi sonuçlarına göre;

Toplam Kalite için; 3-4 yıl ve 4-5 yıl süre ile spor yapanların algısı 1-2 ve 7-8 yıl spor yapanlardan anlamlı derecede daha yüksektir. Ek olarak 1-2 yıl ve 4-5 yıl spor yapanların algı düzeyi 7-8 yıl spor yapanlardan, 5-6 yıl spor yapanların algı düzeyi 4-5 yıl ve 7-8 yıl spor yapanlardan anlamlı derecede daha yüksektir.

Müşteri çalışan etkileşimi için; 3-4 yıl süre ile spor yapanların algı düzeyi 1-2,4-5 ve 7-8 yıl süre ile spor yapanlardan anlamlı derecede daha yüksektir. Ek olarak 1-2 yıl ve 4-5 yıl spor yapanların alg1 düzeyi 7-8 yıl spor yapanlardan, 5-6 yıl spor yapanların algı düzeyi 4-5 yıl ve 7-8 yıl spor yapanlardan anlamlı derecede daha yüksektir.

Tasarım alt boyutu için; 5-6 yıl spor yapanların ortalaması 1-2 yıl, 4-5 yıl ve 7-8 yıl süre ile spor yapanlardan, 3-4 yıl spor yapanların ortalaması 4-5 yıl ve 7-8 yıl spor yapanlardan, 1-2 yil ve 4-5 yil spor yapanların ortalaması da 78 yıl spor yapanlardan anlamlı derecede daha yüksektir.

Fiziksel değişim alt boyutu için; 3-4 yıl ve 5-6 yıl spor yapanların ortalaması 1-2, 4-5 ve 7-8 yıl süre ile spor yapanlardan anlamlı derecede daha yüksektir. EK olarak 1-2 yıl ve 4-5 yıl spor yapanların ortalaması 7-8 yıl süre ile spor yapanların ortalamasından anlamlı derecede daha yüksektir.

Bilgi, malzeme, program çeşitliliği alt boyutları için; ; 3-4 yıl ve 5-6 yıl spor yapanların ortalaması 1-2, 4-5 ve 7-8 yıl süre ile spor yapanlardan anlamlı derecede daha yüksektir. EK olarak 1-2 yıl ve 4-5 yıl spor yapanların ortalaması 7-8 yıl süre ile spor yapanların ortalamasından anlamlı derecede daha yüksektir.

Sosyalleşme için; 3-4 yıl spor yapanların ortalaması 1-2, 4-5 ve 7-8 yıl süre ile spor yapanlardan anlamlı derecede daha yüksektir. Ek olarak 5-6 yıl süre ile spor yapanların ortalaması $4-5$ yıl ve 7-8 yıl süre ile spor yapanların ortalamasından anlamlı derecede daha yüksektir. 1-2 yıl ve 4-5 yıl spor yapanların ortalaması da 7-8 yıl süre ile spor yapanların ortalamasından anlamlı derecede daha yüksektir.

Birleşme değeri alt boyutu için; 5-6 yıl süre ile spor yapanların ortalaması 1-2, 4-5 ve 7-8 yıl süre ile spor yapanların ortalamasından, 3-4 yıl süre ile spor 
yapanların ortalaması 4-5 yıl ve 7-8 yıl süre ile spor yapanların ortalamasından, 1-2 yıl ve 4-5 yil spor yapanların ortalaması ise 7-8 yıl spor yapanların ortalaması 7-8 yıl spor yapanların ortalamasindan anlamlı derecede daha yüksektir.

Müşteriler arası etkileşim için 5-6 yıl süre ile spor yapanların ortalaması diğer tüm gruplardan anlamlı derecede daha yüksektir. 3-4 yıl süre ile spor yapanların ortalaması 1-2 yıl, 4-5 yıl ve 7-8 yıl süre ile spor yapanlardan anlamlı derecede daha yüksektir. Ek olarak 1-2 yıl ve 4-5 yıl süre ile spor yapanların ortalaması 7-8 yıl süre ile spor yapanlardan anlamlı derecede daha yüksektir.

Çalışma zamanı alt boyutu için; 3-4 yıl ve 5-6 yıl süre ile spor yapanların ortalaması 1-2 yıl, 4-5 yıl ve 7-8 yıl süre ile spor yapanlardan anlamlı derecede daha yüksektir. Ek olarak 4-5 yıl süre ile spor yapanların ortalaması 1-2 yıl ve 7-8 yıl süre ile spor yapanlardan anlamlı derecede daha yüksektir.

\section{Güvenirlik Analizi}

Çalışmada kullanılan ölçeğin güvenilirlik düzeyinin belirlenmesi için güvenilirlik analizi yapılmış ve chronbach alfa katsayısı elde edilmiştir.

Cronbach' s Alfa Katsayısının değerlendirilmesinde uyulan değerlendirme ölçütü;

$0.00 \leq \alpha<0.40$ ise ölçek güvenilir değildir.

$0.40 \leq \alpha<0.60$ ise ölçek düşük güvenilirliktedir.

$0.60 \leq \alpha<0.80$ ise ölçek oldukça güvenilirdir.

$0.80 \leq \alpha<1.00$ ise ölçek yüksek derecede güvenilirdir.

Aşağıda verilen tabloda elde edilen chronbach alfa katsayıları verilmiştir.

\begin{tabular}{ll}
\hline & Chronbach alfa \\
\hline Toplam Kalite & 0,825 \\
\hline Müşteri-Çalışan Etkileşimi & 0,808 \\
\hline Tasarım & 0,817 \\
\hline Fiziksel Değişim & 0,909 \\
\hline Bilgi & 0,923 \\
\hline Sosyalleşme & 0,789 \\
\hline Malzeme & 0,788 \\
\hline Program Çeşitliliği & 0,869 \\
\hline Birleşme Değeri & 0,825 \\
\hline Müşterilerarası Etkileşim & 0,911 \\
\hline Çalışma Zamanı & 0,859 \\
\hline
\end{tabular}




\section{Tartışma ve Sonuç}

Bu çalışmada, spor merkezi üyelerinin beklentilerini ve algılanan hizmet kalitesi düzeylerini öngören değişkenlerin araştırılması amaçlanmıştır. Yerel belediyelerin verdikleri hizmete yönelik kalite algıları ("program çeşitliliği", "çalışma zamanı", "bilgi", "müşteri-çalışan etkileşimi", "müşteriler arası etkileşim", "fiziksel değişim", "birleşim değeri", "sosyalleşme", "tasarım", "malzeme") ile "cinsiyet", "yaş", haftalık spor günü sayısı", "spor yaptığı y1l" değişkenlerine göre karşılaştırmaktadır.

Cinsiyet değişkeni için; kadınların bilgi, program çeşitliliği ve çalışma zamanı alt boyutlarında erkeklere göre, bağımsız gruplarda $t$ testi sonuçlarına göre; bilgi, program çeşitliliği ve çalışma zamanı alt boyutları cinsiyete göre anlamlı düzeyde farklılık göstermektedir. Kadınların "bilgi", "program çeşitliliği" ve "çalışma zamanı" alt boyutları düzeyi erkeklerden anlamlı derecede daha yüksek olduğu tespit edilmiştir. Bunun nedeni, kadınların erkeklere oranla daha fazla serbest zamanı olmasından dolayı erkeklere oranla daha fazla çalışma zamanına, daha farklı spor branşları ve bu konularla ilgili daha fazla bilgi sahibi olmak istemektedirler. Bu bulgular ise Eraslan (2014)'ve Greenwell ve arkadaşlarının (2004) çalışmalarıyla örtüşürken Kim ve Kim (1995), Yüzgenç (2010) ve Demirel (2013)'in çalışmalarıyla farklılık göstermektedir. Yerel yönetimlerin işlettiği spor merkezlerinde de yöneticiler kadınlara yönelik daha fazla program çeşitliliği ve erkeklere oranla özellikle gündüz saatlerinde daha uzun süreli seanslar tasarlayabilirler.

Yaş değişkeni için; toplam kalite algısı, müşteri çalışan etkileşimi, tasarım, fiziksel değişim, bilgi, sosyalleşme, malzeme, program çeşitliliği, birleşme değeri, müşteriler arası etkileşim ve çalışma zamanı alt boyutları için 18-30, 5160 ve 60+ yaş grubu kişilerin ortalaması $31-40$ ve 41-50 yaş grubu kişilerden anlamlı derecede daha yüksektir. Bu sonuç ise Ergin (2010) ve Eraslan (2014) çalışmasıyla örtüşmemektedir.

Haftalık spor gün sayısı değişkeni için "Müşteri çalışan etkileşimi”, "tasarım", "fiziksel değişim", "bilgi ve sosyalleşme", "malzeme", "program çeşitliliği", "birleşme", "müşteriler arası etkileşim ve çalışma zamanı" alt boyutları için 3 gün spor yapanların algı düzeyi diğer tüm gruplardan anlamlı derecede daha yüksektir. Dolayısıyla haftada tesis kullanım sayısına göre kalite 
algılamaları değişmektedir. Bu sonuçlar Demirel (2013)'in çalışmasıyla benzerlikler gösterirken Eraslan (2014) ve Yüzgenç (2010) çalışmamalarıyla örtüşmemektedir.

Katılımcıların spor yılı değişkeni için; toplam kalite 3-4 yıl ve 4-5 yıl süre ile spor yapanların; müşteri çalışan etkileşimi için 3-4 yıl süre ile spor yapanların; tasarım alt boyutu için; 5-6 yıl spor yapanların; fiziksel değişim alt boyutu için 3-4 yıl ve 5-6 yıl spor yapanların; bilgi, malzeme, program çeşitliliği alt boyutları için 3-4 yıl ve 5-6 yıl spor yapanların; sosyalleşme için 3-4 yıl spor; birleşme değeri alt boyutu için 5-6 yıl süre ile spor yapanların; müşteriler arası etkileşim için 5-6 yıl süre ile spor yapanların; çalışma zamanı alt boyutu için 3-4 yıl ve 5-6 yıl süre ile spor yapanların ortalaması diğerlerinden anlamlı derecede daha yüksektir. Bu sonuçlar Demirel (2013), Memiş ve Ekinci (2007) Ceyhun (2006)'un çalısmasıyla benzerlikler gösterirken Eraslan (2014) ve Yüzgenç (2010) çalışmamalarıyla örtüşmemektedir.

Sonuç olarak, sosyal değişimlerin ve dönüşümlerin bilinçli tüketicileri ortaya çıkarmada aktif bir rol oynadığı düşünülebilir. Bu nedenle spor merkezi üyelerinin gittikleri spor merkezlerini bir boyutta değerlendirmedikleri söylenebilir. Spor merkezlerinin fiziksel unsurları bireylerin temel ihtiyaçlarını karşılamaktadır. Bununla birlikte, sosyalleşebilecekleri ortamın ve insan ilişkilerinin ön planda olduğu gerçeğinin, müşterilerin temel beklentilerini karşlamada önemli olabileceği yerel yönetimler tarafından düşünülmelidir. Müşteriler aldıkları hizmetlerin kaliteli olmasını istemekte ve beklentileri her geçen gün yükselmektedir. Hizmet kalitesi ve müşteri beklentilerini karş1lama, işletmelerin varlıklarını sürdürme yeteneğinin önemli bir göstergesi olduğundan, hizmet kalitesinin doğasını ve müşteri beklentilerini anlamak için çok faktörlü araştırmalar yapılmalıdır. Hizmet ve ölçüm araçlarının kalitesi değişen dünya koşullarında yeni araştırma konularına müşteri beklentilerinin eklenmesi ve kapsamlı araştırmaların yapılması önerilmektedir. 


\title{
EXTENDED ABSTRACT
}

\section{Examining the Perceived Service Quality Levels of Recreational Sports Facilities Members}

\author{
Arif Çetin - Ayşe Demir \\ İstanbul Aydin University
}

At the present time, with modern city life exercise become a popular activity and offers a wide range services to both public and private sector customers in sports center. However, these enterprises face financial difficulties due to the increasing competition in the markets. For this reason, the service quality of sports centers appears to be the most important factor in solving financial difficulties (Jung and Choi, 2016). This interest in sport has developed positively in the past two decades, with physical, psychological and social well-being, and has led to improved quality of life for people. The concept of sports management has become more challenging due to the many tasks and actions involved and there is an increasing need to implement adequate quality assessment programs to improve sports services (Castillo-Rodriguez, Onetti-Onetti and Chinchilla-Minguet, 2019). Fitness centers tend to provide services at the best price and time to maintain their existence and meet customers' expectations and needs for sports. Therefore, learning customer demands and expectations is an important component to ensure that sports services can provide customer needs (Howard and Crompton, 1980). This study is important in terms of determining customer expectations in sports centers and investigating perceptions of service quality and determining what kind of services should be offered in these enterprises. In this study, it was aimed to investigate the variables that predict the expectations of the sports center members and their perceived service quality levels. It is thought that the research findings will bring suggestions together with relevant concrete evidence to improve the service quality in public and private sports centers. In addition, this study aims to help us estimate to what extent customer satisfaction and expectation will determine fitness center preferences in the future. 
In this research, the research group was formed by voluntary sampling method among the active members of the 2 swimming pools and 2 sports halls operated by Zeytinburnu Municipality. With this method, 372 people participated in the study and when the distribution of participants by gender is examined; the proportion of women is $64 \%$ and the proportion of men is $36 \%$. When the distribution by age groups is examined; The proportion of people in the $18-30$ age group is $23.4 \%$, the proportion of people in the $31-40$ age group is $38.7 \%$, and the proportion of people in the $41-50$ age group is $18.3 \%$. The proportion of $51-60$ age group is $17.2 \%$ and the proportion of $60+$ age group is $2.4 \%$. When the distribution according to the educational status is examined; the rate of primary school graduates is $20.4 \%$, the ratio of high school graduates is $39.8 \%$, the rate of associate degree graduates is $25.5 \%$, and the ratio of undergraduate graduates is $14.2 \%$. When the income groups are analyzed, $61.6 \%$ of the participants are in the $2000-3000$ TL, $29.6 \%$ are in the $3000-4000 \mathrm{TL}, 5.9 \%$ are in the $5000-6000 \mathrm{TL}$ and $3 \%$ are in the 6000-7000 income group. When the distribution according to the number of sports days is examined; $11.2 \%$ of those who do sports 1 day a week, $35.8 \%$ of those who do sports 2 days, $35.8 \%$ of those who do sports 3 days, $4.6 \%$ of those who do sports 4 days, $12.9 \%$ of those who do sports 5 days. When the range according to the year of sport is examined; the proportion of those who do sports for 1-2 years is $20.7 \%$, the proportion of those who do sports for 3-4 years is $19.4 \%$, the proportion of those who do sports for $4-5$ days is $26.1 \%$ and the proportion of those who do sports for 5-6 days is $16.9 \%$. The first part of the study as a data collection tool generated questions about the participants' age, gender, educational status, income, the number of days and years they did sports. In the second part, "The Scale of Recreational Sports Services", which was validated and trusted by Köşker Demir and Çimen (2012), was used to determine the service perceptions of the participants in local government sports facilities. The scale is $10 \mathrm{sub}-\mathrm{di}$ mensional and it consists 38 articles. These sub-dimensions are "program diversity" (Article 3), "working time" (article 2) "information" (Article 4), "customer-employee interactions" (Article 6), "interaction between customers" (Article 2) "physical change" (Article 5), "joining" (Article 2), socialization (Article 3), "design" (Article 5), "material" (4 items total). For the gender factor; women differ from men as program diversity and working time in sub-dimensions. Also, according to the results taken from independent 
groups of t-test; the sub-dimensions of information, program diversity and working time make an important significance according to the gender. It's estimated that women's sub-dimensions of "program diversity" and "working time" are significantly higher than men. The reason is that women have more free time than men, so they want to have more working time, more different sports branches and more information about these issues than men. For the age factor, individuals between 18-30, 51-60 and 60+ are higher than the individuals 31-40 and 41-50 as in sub-dimensions of the perception of total quality, customer-employee interaction, design, physical change, information, socialization, material, program diversity, the value of joining, interaction between customer and working time. For the weekly sports factor, those who do sports for 3 days have significantly higher perception than all the groups as in the sub-dimensions of "customer-employee interaction", "design", "physical change", "information and socialization", "material", "program diversity", "joining", "interaction between customers and working time". Therefore, perceptions of quality vary according to the number of service area used per week. As a result, it can be considered that social changes and transformations play an active role in eliciting conscious consumers. For this reason, the members of the sports center can be said that they do not evaluate the sports centers they go to in one dimension. Physical elements of sports centers meet the basic needs of individuals. However, it should be considered by local authorities that the environment in which they can socialise and the fact that human relationships are at the forefront can be important in meeting customers' basic expectations. Customers demand the services they receive to be qualified and their expectations are increasing day by day. Since service quality and meeting customer expectations are an important indicator of businesses' ability to sustain their assets, multifactor research must be undertaken to understand the nature of service quality and customer expectations. It's recommended that adding customer expectations in new research topics and carrying out an extensive research should be done in changing world conditions in terms of the quality of service and measurement tools. 


\section{Kaynakça / References}

Aras, H.; Çimen, K. ve Bal, F. (2019). Fiziksel egzersiz hizmetlerinde algilanan hizmet kalitesinin değerlendirilmesi: Ankara Bfit örneği. Journal Of Social, Humanities and Administrative Sciences, 5(21), 1323-1332.

Castillo-Rodriguez, A., Onetti-Onetti, W., ve Chinchilla-Minguet, J. L. (2019). Perceived quality in sports centers in Southern Spain: A case study. Sustainability, 11(14), 3983.

Ceyhun, S. (2008). Spor tesislerinin rekreatif açıdan kullanımı. Kastamonu Eğitim Dergisi, 16(1), 325.96.

Demirel, H. N. (2013). Rekreasyonel spor/fitness programı sunan işletmelerde hizmet kalitesi. Doktora Tezi, Gazi Üniversitesi Sağlık Bilimleri Enstitüsü, Ankara, 31.95.

Eraslan, A. (2014). Üniversite yerleşkelerindeki rekreasyonel spor merkezlerinde hizmet kalitesi. Yayınlanmamış Yüksek Lisans Tezi, Gazi Üniversitesi Sağlık Bilimleri Enstitüsü.

Greenwell, F., ve Pastore DL. (2004) Perceptions of the service experience: Using demographic and psychographic variables to identify customer segments. Sport Marketing Quarterly, 11(4), 233-241.

Im, Y.S., O, Y.P. ve Kim, J.P. (2015). The effect of customer service guarantee of sports centers on service quality, service reliability, service value, and customer loyalty. The Korea Journal of Sport, 13(4), 345-362.

Islamoğlu, I. (2019). Özel spor merkezlerindeki hizmet kalite algisi. Journal of International Social Research, 12(65), 1112-1117.

Jung, W.J. ve Choi, J.Y. (2016).The relationship between service quality, service satisfaction, and repurchase intention of participants in sports centers. The Korean Journal of Sports Science, 25(2), 521-531.

Kaya, L. Yücedağ, C , Aşıkkutlu, H. ve Keskin, R . (2019). Üniversite fitness merkezlerinde kullanıc memnuniyetinin incelenmesi: MAKÜ vePAÜ örneği. Uluslararasi Mühendislik Tasarm ve Teknoloji Dergisi , 1(1) , 1-9.

Kim, D., ve Kim, S.l Y. (1995). QUESC-An instrument for assessing the service quality of sport centers in Korea. Journal of Sport Management, 9, 208-220.

Kim, H.J. ve Han, S.R. (2013). The effect of sports centers' service guarantee on service quality, service value, customer satisfaction and customer loyalty. Journal of Digital Convergence, 11(9), 127-138.

Kim, K.S. (2006). The relationship among organizational culture, job satisfaction, and organizational commitment of public sports facilities. The Korean Journal of Physical Education, 45(6), 145-155. 
Memiş, U. A., ve Ekenci, G. (2007). Spor merkezlerinde müşteri memnuniyeti: Ankara İi örneği. Gazi BESBD 12(1), 33-48.

Rhee, S.D., Lee, J.B. ve Lee, J.H. (2006). The effects of relationship benefits perceived by the participants of leisure activity on the satisfaction from sports centers and consumer loyalty. Korean Journal of Sport Management, 11(3), 77-90.

Silvestro, R. (2002). Dispelling the modern myth: Employee satisfaction and loyalty drive service profitability. International Journal of Operations $\mathcal{E}$ Production Management, 22(1), 30-49.

Yu, H. S., Zhang, J. J., Kim, D. H., Chen, K. K., Henderson, C., Min, S. D., ve Huang, H. (2014). Service quality, perceived value, customer satisfaction, and behavioral intention among fitness center members aged 60 years and over. Social Behavior and Personality: An international journal, 42(5), 757-767.

Yüzgenç, A. A. (2010). Yerel hizmetlerin sunduğu spor hizmetlerinde hizmet kalitesi. Yüksek Lisans Tezi, Gazi Üniversitesi Sağlık Bilimleri Enstitüsü, Ankara, $19,34,43-44,68.94$.

\section{Kaynakça Bilgisi / Citation Information}

Çetin, A. ve Demir, A. (2021). Rekreasyonel spor tesisleri üyelerinin alg1lanan hizmet kalitesi düzeylerinin incelenmesi. OPUS-Uluslararası Toplum Araştırmaları Dergisi, 17(33), 425-446. DOI: 10.26466/opus.677521 